\section{A NOTE ON THE MODE OF ACTION OF IODINE.}

Br DAWSON TURNER, M.D.EDIn., M.R.C.P.Lond., lecturer on Physies, Surgeons' Hall, Edinburgh.

The value of iodine as an absorbent has long been known. It is used to cause the absorption of enlarged glands, of serous effueions, and of thickenings due to chronic inflammations; and this action is believed to be due to a stimulation of the lymphatic system.

Perhaps the most remarkable results due to the action of a compound of iodine in producing absorption are those which were attained by Major Holmes and Captain Cunningham in the treatment of goitre in India. They recommended that the enlarged thyroid should be smeared over with the red iodide of mercury ointment, and that then the patient should be made to sit with his neck exposed to the rays of the sun or of a hot fire for many hours. The results were extraordinary.

Sixty thousand natives were treated in two years, and a cure was commonly effected.' My object in this communication is to offer a suggestion, from the point of view of the physicist, as to the mode of action of the iodine in these cases. Iodine is used in physical experiments to cut off the visible rays of the spectrum. A solution of iodine in bisulphide of carbon will quench the visible rays of the sun, but will transmit the invisible heat rays. The solution is remarkably transparent to the heat rays; it is diathermanous. Now, the fact that Major Holmes found that the action of the ointment was much intensified by exposing the patients to the direct rays of the sun has appeared to me to depend upon the pliysical action of the iodine that $I$ have mentioned. At any rate, $I$ offer this as a suggestion. Further, the fact that the red iodide is so efficacious points in the same direction. because the red substance would also serve to transmit chiefly the heat rays. The solar radiation would be filtered by the application, and the gland would be subjected to the full blaze of the calorific rays without the vibrations of its moleculfs being interfered with by the visible rays. Professor Tyndall ${ }^{2}$ made some experiments with paper reddened by the red iodide of mercury, and found that it was also very transparent to heat rays; it therefore falls into line with simple iodine. If this suggestion as to the mode of action of iodine be correct, we do wrong in covering up diseased parts to which iodine has been applied; we ought rather to expose them freely to the sun's raps.

\section{SUCCESSFUL LIGATURE OF COMMON CAROTID FOR SECONDARY H FMORRHAGE FROM INTERNAL MAXILLARY : TRANSFUSION OF SALINE SOLUTION.}

BY S. EDWARDS JONES, L.R.C.P., L.R.C.S.EDIN., ETc., 'Late Senior House-Surgeon, Glasgow Royal Infirmar y; Is-y-coed, Wrexham.

I RRCORD the following case for two reasons: 1 . The usually high percentage of mortality in ligature of the carotid for secondary hæmorrhage. 2 . The benefit accruing from the transfusion of a saline solution.

F. L., aged 55, a coal dealer, was admitted on March 15th. 1894, to Glasgow Royal Infirmary, under Professor Knox, for epithelioma of the lip and malignant tumour of inferior maxilla of about two years' duration.

On March 21st, under chloroform, Dr. Knox excised the left half of the inferior maxilla. The hæmorrhage was free, but well under control.

The patient progressed favourably. The external wound healed by first intention, and the temperature was normal, but there had been a foul discharge from the mouth. On April 2nd profuse bleeding set in, coming from the left side of the mouth. An attempt was made to coming irom the left side of the mouth. An at it prom the mouth, which proved of no avail; Dr. Knade an contr(l) it from the mouth, which proved of no avail; Dr. Kn.ox made an incisiou along the course of the former wound, and by the free use of the actual cautery succeeded

The foul discharge increased on April 5th and 6th, and the gauze on
then packed with gauze. the face wound was changed frequently. No bleeding occurred until the night of April 7th. when it became of a very severe character. From the diffeulties experienced in the attempt to arrest it before, and the failure

1 Quain's Dictionary of Medicine, Goître.
\& Heat as a Mode of Motion, chap. xiii. to prevent a recurrence, I decided, in the absence of Dr. Knox, to at once cut down upon and ligature the common carotid on the left side. (hlolofurm was administered, and the shoulders having been clevated, an incision was mide ?!' inches long opposite tho thiroid and along the course of the inucr euge of the sterno-mastoid. Tlie skin and platyina we divided the anterior jugular avoided, the deepcervical fasciacut throunl and the steruo-inistoid and theomo-hyoid deepcervical pasciacut through, and the sterting muscles having been thislaced, the cearotit sheath was exposed with the up endell soln nerve in tront of $A$. $A$ pieno sheath was then pinched up, a sinall opening made in posed for a quarter of an inch. An ancurysm needle, with a strong aseptic ligature of silk, was passed behind the artery from without in wards, and tied. At the time of tightening the ligature the breathing was hardly appreciable, but it improved in a few seconds. The wound was then douched out with carbolic, 1 in 10 , dried, dusted with iocloform, a strand of catgut leit in for drainage, and the wound sutured. Dressinge were then applied.

The patient was pale, covered with a clammy sweat, and the radial pulse could not be felt. It was decided to transfuse. The median cephalic was opened, and 20 ounces of a warm saline solution iufused. The patient seemed to revive in a few seconds, the pulse became appreciable, and the skin warmer. He was a little restless immediately after the operation, but a morphine suppository (a quarter of a grain) was given, and he passed a good night.

given, and he passed a good night. Ader the operation he on one or two occasions complained ofsium in 20-grain des dribbling from the face wound On three occasions a small amount of blood oozed from mouth, but it was overcome easily by packing from external wound. There was no pulsation in the carotids or temporaarteries above seat of ligature. The general condition of the patient on May 12th was good. With the exception of the slight headache he had suf ered no ill-effests from the ligature. The temperature was normal.

I have no doubt in my own mind, and this is also borne out by Dr. Knox, that the bleeding in this case was from some branches, if not from the main trunk, of the internal maxillary.

It may be asked : Why was no attempt made to ligature the external carotid? My reasons were that: First, we had a wound on the face, communicating with the month, which. wound could not be kept aseptic. A continual dribbling down the neck could not be always avoided, however great our care, and this circumstance offered but a poor chance to the perfect healing of a wound in its immediate proximity; indeed, it affected the wound made, although some distance away. Secondly, where seconds were a consideration it was only right that I should choose the least difficult operation.

Was the oozing mentioned a recurrence? I think not. I put it down as due to the sloughing which continued for some time from the interior of the mouth; it could not have comefrom any large vessel, as it was so easily controlled bp packing.

The moriality from this operation, however, is so highaccording to Guthrie over 50 per cent.- that nnder more favourable circumstances as regards the choice of a site for an incision, I should, if called upon in fature, ligature the external carotid, which must be the much less dangerous procedure.

The shock from the ligature, considering that the patient (1) lost so much blood, (2) was recovering from the effects of a severe operation, and (3) the deprivation of the brain for the time being of half its blood supply, was very small indeed. Whether the rapidity of his recovery could be accounted for by the infusion of saline solution ( 20 ounces) is a matter for investigation. I may say, however, that in six cases of transfusion which I have seen, two of which I did myself, the change in a few seconds has been remarkable, and in all these cases has been followed by good results. The solution used in the case was: $\mathbb{F}_{k}$ Sodium chloride $3 \mathrm{ij}$, sodium phosphate 3 \&s to 20 ounces of warm water.

Medical Protection iv Rove.-The medical practitioners of the citv and province of Rome have determined to form a "College" or association for the protection of their interests not only in their relations with patients, but against public authorities and hospital governing bodies. At a recent meeting of the Societa Lancisiana, an elaborate report on the scheme, which has been for a considerable time in contemplation, was presented by Professor Sciamanna, and a provisional executive committee was formed to carry the proposal into effect. The members of the committee are Professors Sciamanna, Marchiafava, and Postempski, and Drs. Parisotti. Bertini, Mazzoni, Impaccianti, Torti, and Rossoni. The provisional committee has power to add to its unmber by inviting six of the best-known and most influential practitioners in the Italian capital to join it. 